\title{
RETROSPECT OF BREEDING FOR GENETIC RESISTANCE TO DISEASES IN POULTRY AND FARM ANIMALS
}

\author{
A. K. DAS* , H. NIANG, A. K. SAHOO \\ S. KUMAR ${ }^{1}$ AND D. DAS ${ }^{2}$ \\ Department of Animal Genetics and Breeding \\ F/o Veterinary and Animal Sciences \\ West Bengal University of Animal and Fishery Sciences \\ 37, K. B. Sarani, Kolkata-700 037, West Bengal, India
}

Disease occurs when environmental insult meets genetic predisposition while interaction goes between the genotype of an individual and the environment where it grows. Antigenic drift of the pathogens usualiy has minor or no effects on the polygenic type of defense mechanisms which include a variety of different physiological and anatomical characteristics acting together to invoke resistance. There is potential for selecting for resistance between and within populations as genetic variation in diseases is ubiquitous, and genetically heterogenous populations are important in maintenance of resistance. Genetic control of disease can be advanced through selecting locally adapted breeds, selective breeding utilizing disease resistant individuals, and implementing cross-breeding methods to introgress the resistant genes. Integration of chemotherapeutic agents and antibiotics management, vaccination protocols, grazing and nutritional management, culling and stress reduction practices along with other measures must accompany genetic approaches to reduce the impact of livestock disease on profitability and animal well being.

Key words : Disease resistance, Genetic selection, Immuneresponse and immunomodulation, MAS, Transgenic breeding

Poultry and farm animals constitute livestock sector, an integral part of rural livelihoods, agriculture, national economy and community development. Disease affects the sustainability and competitiveness of a community (Whitelaw and Sang, 2005) and diseases affecting livestock can have a significant impact on animal productivity and production, human health, and consequently, on the overall

*Corresponding author

${ }^{1}$ Division of Avian Genetics and Breeding, ICAR-Central Avian Research Institute, Izatnagar-243122, U.P. ${ }^{2}$ ICAR- Indian Veterinary Research Institute, Izatnagar, Bareilly-243122, U.P. 
process of economic development (Jovanovic et al., 2009). Disease costs directly as high as $35-50 \%$ of turnover within the livestock sector in the developing world (Bishop and Woolliams, 2014) excluding underlying indirect and intangible costs disease variably incurs while food safety and quality (residues in livestock products) is concerned and disease poses zoonotic threats to human health, renders reservoir host for infections, creates pressures on breeders to address welfare issues and to reduce the reliance of production systems on conventional control strategies. Further, unjudicious use of chemotherapeutic agents, antibiotics and vaccination protocols have most frequently had negative consequences by prompting variability among micro-organisms and inducing appearance of drug-resistant strains, which has resulted further in serious animal healthcare problems and adverse effects on environment. Hence, disease impacts are often considered to be a qualitative function of direct economic impact, industry and public concern, zoonotic potential and impacts on animal welfare and international trade (Davies et al., 2009; Bishop and Woolliams, 2014). Keeping these aspects in view, present strategy strives for sustainable control of diseases by integration of herbal chemotherapeutic agents and antibiotics management, vaccination protocols, grazing management, nutritional management, biological and genetic control understanding host-pathogen interaction. Breeding programs with the goal of enhancing resistance to diseases may help to alleviate the problems for long time. Selection of livestock with natural and acquired resistance to disease is one such option for alternative control of disease (Selvam and Panneerselvam, 2014). For a subset of diseases, it may be both feasible to measure resistance traits on sufficient animals to determine genotypes for resistance and economically worthwhile to incorporate such traits into breeding goals (Bishop and Woolliams, 2014). Hence, genetics of disease resistance, genomic tools in selecting resistance phenotypes, its sustainability and introgression into deserving population were reviewed and accordingly breeding strategy was framed for enhanced resistance to diseases in livestock.

\section{Concepts of disease resistance, tolerance and resilience}

The disease resistance is inherently a relative term rather than absolute and implicitly confuses infection (invasion by a pathogen or parasite) with disease (the negative consequences of being infected) (Bishop and Woolliams, 2014). From an ecological consideration of the interaction between the host and the pathogen species (Grenfell and Dobson, 1995), the concept, resistance may be defined as the ability of the host to exert some degree of control over the pathogen life cycle (Bishop, 2012; Bishop and Stear, 2003) or to resist infection (Jovanovic et al., 2009), while tolerance signifies a condition in which the infected host displays very limited adverse 
effects (Jovanovic et al., 2009) as the net impact on performance of a given level of infection, i.e. the regression of performance on (a function of) pathogen load and a related concept, resilience implies the productivity of an animal in the face of infection (Bishop and Woolliams, 2014). Whereas resistance refers the ability of a host exerting a deleterious influence on the fitness of the pathogen, hosts with a greater tolerance are those able to maintain a greater fitness as pathogen load increases (Bishop and Woolliams, 2014). If our goal is to stop the spread of infection to another population, then resistance is far more advantageous than tolerance (Jovanovic et al., 2009). If a correlation exists between the resistance, tolerance and/or resilience, then there may be applicable an equation, $W_{i}=a_{i}+b_{i} I$; where $a_{i}$ is the fitness when uninfected, $I$ is the infection intensity, $W_{i}$ is the actual fitness of host type $i, b_{i}$ is what shows us tolerance (i.e. the slope of relationship between $W$ and $I$ ) (Stowe et al., 2000). As immune response alters at an individual level with continuing exposure to infection even conditioning husbandry and environment as constant as possible, it is difficult to measure the change in performance as pathogen load changes to assess tolerance but can only be measured for those diseases with weak immune memory and the traits expressed repeatedly through life (Bishop and Woolliams, 2014). Again to assess tolerance requiring different infection levels on an individual animal can be overcome to some extent by considering host genetics at the family level where sire's genetic merit can be considered as a reaction norm based on observations on its offspring with different pathogen burdens, but the family size has to be sufficient to minimize between-sib variability (Bishop and Woolliams, 2014). Some of the measurement issues associated with tolerance may be overcome by the hostpathogen interaction trajectories (DoeschlWilson et al., 2012), which describe the joint changes in animal infection level and performance over time accounting for timedependent impacts of infection and lending themselves to mathematical analyses. The bigger issue with tolerance is that it is only expressed by the infected animals and to be useful, requires the disease to be at high prevalence (Bishop, 2012). However, Bishop and Woolliams (2014) could believe for those diseases where prevalence is substantially less than one, that genomic studies should focus on resistance traits rather than tolerance, and in cases where all animals are infected, then resilience should become a useful concept.

\section{AnGR perspective for genetic variability in disease resistance/ tolerance}

Genetic investigations involving animal resistance to infections caused by pathogens of varying etiologies can be carried out at three genetic levels i.e. species, breed and individual to assess animal genetic variability. The impact of genetic resistance/ tolerance to pathogens is high when all levels of genetic resistance/ tolerance acts synergistically. Studies on 
species variability in genetic resistance to pathogen causing footrot indicate that goats display a greater resistance to footrot than sheep. When considering the significance of resistance/tolerance at the breed level, the intrinsic evolutionary advantage of breeds that are adapted to an environment should be taken into account (Jovanovic et al., 2009). In tropical regions, where extreme endemic diseases are widespread due to their evolutionary roots, locally adapted autonomous breeds display a far greater level of genetic resistance/ tolerance and adaptation, as compared to imported breeds (Savic et al., 1995). Individual variability and the identification of those individuals whose resistance/ tolerance to the infective agents can be determined through clinical examination, or estimating resistance indicator parameters or using genentic markers (marker-assisted slection) or genomic tools, represents the first step in the formation of genetic resistance/ tolerance within a population (Jovanovic et al., 2009). Based on the database FAO DAD-IS (2007), genetic resistance/ tolerance to a variety of diseases, has been reported in 59 breeds of cattle, 33 breeds of sheep, 5 breeds of horses and three breeds of pigs, all of which confirms that certain breeds express greater resistance/ tolerance to pathogens than others.

Cattle: Studies on genetic resistance in cattle aimed at so-called target diseases, those that cause enormous economic loss or at investigations geared at developing management programs for implementation in regions where a particular infectious disease is endemic in character (Jovanovic et al., 2009). Zebu cattle (Bos indicus) appear to be resistant to foot and mouth disease (FMD), rinderpest and tick borne diseases, to which European cattle (Bos taurous) are susceptible (Selvam and Panneerselvam, 2014). In Herefold cattle, presence of pigment around the eye indicates that the animal is resistant to eye infections and eye cancer. Selection of breeding stock with pigment on eye-lids drastically reduces the eye trouble (reviewed in Selvam and Panneerselvam, 2014). Rinderpest, mastitis and dermatophilosis were documented for breed resistance; paratuberculosis and salmonellosis for within-breed resistance; tuberculosis and brucellosis for within and between-breed resistance; FMD, trypanosomosis, theileria ( $T$. annulata), East coast fever (T. pava) and babesia for breed tolerance; and theileria (T. sergenti), helminthosis and ticks-infestation for resistance and tolerance in combination (reviewed in Jovanovic et al., 2009; Bishop et al., 2002).

Sheep and goats: Small ruminants while raised on grazing system naturally get exposed to parasitic infection caused by helminths. Sheep and goats display between-species variation in resistance to gastrointestinal nematode infections, mycotoxins, bacterial diseases including footrot and mastitis, ectoparasites such as lice and scrapie (Selvam and Panneerselvam, 2014). Mastitis, 
dermatophilosis and cutaneous myiasis (flystroke) were documented for demonstrating for breed resistance; paratuberculosis and salmonellosis for within-breed resistance; cowdriosis (heartwater), trypanosomosis for breed tolerance; and helminthosis and liver fluke infestation for resistance and tolerance in combination (reviewed in Jovanovic et al., 2009; Bishop et al., 2002).

Pigs: Special effort identified neonatal diarrhea $(E$ coli $\mathrm{F} 4 / \mathrm{F} 5)$ and post weaning diarrhea $(E$ coli $\mathrm{F} 18)$ with complete resistance (major gene conveys), atrophic rhinitis (Bordetella bronchiseptica) with within and between breed resistance, and African swine fever and FMD with within and between breed tolerance (Bishop et al., 2002). Besides, swine brucellosis (Brucella suis), dysentery (Brachyspira hyodysenteriae), eperythrozoonosis (Mycoplasma suis), leptospirosis, salmonellosis, swine influenza, PCV2 associated disease (Porcine circovirus type 2), vomiting and wasting disease (Haemagglutinating encephalomyelitis virus), Aujeszkys disease (Pseudorabies virus), and few parasitoses (Ascaris suum, Sarcocystis miescheriana, Strongyloides ransomi, Trichinella spiralis) were reported for genetic variation in resistance to pathogens and diseases in swine (Reiner, 2009).

Poultry: Marek's disease, infectious laryngitracheitis, avian infectious bronchitis, Rous sarcoma, pullorum, fowl typhoid, coccidiosis and Ascaridia galli were documented for demonstrating inbred line resistance; and avian leukosis, infectious bursal disease, and Newcastle disease for between-breed resistance (reviewed in Jovanovic et al., 2009; Bishop et al., 2002). Investigations of genetic resistenace to parasitic infections in poultry, determined that breeds varied significantly in their level of resistence to coccidiosis. It was also determined that individuals of the same breed can display marked differences in susceptibility to coccidiosis.

In some cases, the genetic variation is between populations (breeds, strains, lines); in other cases, it exists within populations. In either case, there is potential for selecting for resistance to all these diseases as genetic variation in diseases is ubiquitous. Genetically heterogenous populations are most important in regards to disease resistance maintenance. Diverse populations conferring disease resistance are less susceptible to catastrophic disease epidemics and special attention has been focused on the importance and possible advantages of heteregenous genetic populations, particularly in terms of the complex responses they confer to epidemics, their duration, decreases in mortality, etc. (Springbett et al., 2003). Due to their genetic advantages when in responding to epidemics of catastrohic proportion, the maintenance of genetic heterogeniity in livestock populations is crucial to maintaining viable livestock practices and the preservation of biodiversity (Jovanovic et al., 2009). 


\section{Genetics of disease resistance}

Disease occur when environmental insult meets genetic predisposition (Warner et al., 1987) while interaction goes between the genotype of an individual and the environment where it grows. Resistance or susceptibility to a certain disease or pathogen is usually controlled by a major single gene locus. The defense mechanism may be modulated however by unidentified loci, including genetic regulatory elements, and by environmental factors. The expression of the resistance locus may be a specific predisposing or conditioning factor among a series of other factors. Antigenic drift of the pathogens usually has minor or no effects on this polygenic type of defense mechanisms which include a variety of different physiological and anatomical characteristics acting together to invoke resistance (Muller and Brem, 1991). For instance, fly infestation can be affected by hair/ wool length, skin secretions, hide thickness, and grooming behaviour. The mechanism underlying resistance to pathogen can frequently be explained by the presence or absence of certain molecules in the host which are critical for infection, recognition, or elimination of the pathogen. Typical example is the major histocompatibility complex (MHC) and disease associations. There are also nonspecific defense mechanisms influenced by the expression of major genes such as the activity of lysozymes, interferons, chemokines, phagocytes etc. and also monogenic deficiencies leading to general susceptibility (Muller and Brem, 1991).
The genetic components of disease resistance include those that affect the immune system, as well as virtually every other system of the body, and the most important environmental component is exposure to the pathogen. If a pathogen invades first line of defense, the immune system has the opportunity to eliminate the pathogenic organism through the mobilization of cells and soluble substances produced in the primary (bone marrow and thymus) and secondary (spleen and lymph nodes) organs of the immune system. As reviewed by Warner et al. (1987), cellular immunity is a function of many types of leukocytes, including T cells, macrophages, NK cells, LAK cells, etc. B cells function through developing antibody mediated immunity. Many other soluble molecules to mediate immunity are the complement components, interferons, interleukins, and other lymphokines and monokines. Hormones, prostaglandins and leukotrienes also get involved and cell surface molecules like antigen receptor on B cells (BCR) and on $\mathrm{T}$ cells (TCR) have a role in regulation of the immune response. The TCR recognizes antigens in the context of molecules encoded by the MHC genes. The BoLA (bovine), OLA (goat), CLA (sheep), SLA (pig), B complex (chicken) are the MHC in different domestic species and linked to different specific immunological responses. The high degree of polymorphisms (Adams and Templeton, 1998) for MHC genes which is unique for each individual partially explains how the host immune system can attack such a great 
number of antigens which requires the ability to distinguish self from foreign. The MHC encodes four classes of protein molecules and comprises of three subregions: B-F (Class I), B-G (Class IV) and B-L (Class II), Class III genes mapped outside the Class I and Class II. Class IV genes are unique in avian species and expressed on RBCs. The Class I genes act as restricting dements in $\mathrm{T}$ cell recognition of vitally infected target cells. Thus, the cell receptor recognizes both foreign antigen and self Class I MHC antigens in order to generate an immune response. The Class II (immune response, Ir) genes control the interaction of $\mathrm{T}$ cells, $\mathrm{B}$ cells and macrophages in the generation of the humoral immune response, and participate in some aspects of cellular immunity as well. The function of Class III genes is to be part of the complement cascade, which ends with the lysis of the cell or virus particle to which antibody has bound (Warner et al., 1987). Genetic variation in immune cell compartments naturally exists and may contribute to varied resistance to pathogens (Cheeseman, 2007) as genetic differences in lineage commitment of thymocytes and not selection cause the variation in CD4 and CD8 $\mathrm{T}$ cell populations in mice (van Meerwijik et al., 1998) and the MHC genes determine the peripheral $\mathrm{T}$ cell ratio $(\mathrm{CD} 4 / \mathrm{CD} 8)$ in rats (Damoiseaux et al., 1999). The chicken $\mathrm{MHC}$ as well as non-MHC genes are known to influence B cell mediated antibody responses to various antigens (Lamont, 1991).
There are some non-pathogenic diseases that are strictly genetic and do not involve the immune system. A few of the better known examples are sickle cell anemia, which is caused by a single amino acid substitution in hemoglobin polypeptide chain; Lesch-Nyan syndrome, which is caused by the absence of the enzyme hypoxanthine-guanine phosphoribosyl transferase; and Tay-Sachs disease, which is caused by the deficiency of the enzyme hexosaminidase A (Warner et al., 1987). Some diseases classified as genetic diseases may, in fact, be the inheritance of the receptors (like cell surface receptor K88 in pig) for a specific pathogen (like E. coli to attach) (Moon et al., 1999). In the immune system there are also diseases that are strictly genetic and not dependent on pathogens. In the presence of a pathogen, the ability of an animal to respond immunologically resides in many genes that affect the integrity of the immune system. For instance, the repertoire of cells and antibodies that an individual develops during ontogeny is under genetic control (Warner et al., 1987).

\section{Genetic selection for disease resistance} Animal breeding operates through the selection of genetically superior animals for the important traits exhibiting genetic variation in the population and thus characterized by some degree of heritability. The rate of genetic progress or of response to selection is a function of the accuracy of selection, generation interval and selection intensity. To exploite genetic 
variation in disease resistance, the implications of selection can be wider than just its effect on the population undergoing selection, if we recognize the pathogen-host interaction pathways to understand the epidemiological consequences of the selection and involve in our approach. More important is that three facets of immune system (the natural, innate, and acquired) must be active and is crucial in developing selection programs for disease resistance. If the breeding goal is to reduce bacterial diarrhea in young calves, then selection traits might include the dam's genetic potential for producing specific colostrum antibodies (passive immunity) and the calf's genetic potential for developing an innate and acquired immune system early in life that responds to the diarrhea causing pathogen. There are negative genetic correlations between the dam and calf's resistance to some diseases (Snowder et al., 2005). In this case, selection index for total merit may be feasible to maintain production levels while selecting for disease rsesistance. Interactions between the genetics of the animal and the environment commonly exist, and if found significant, animals selected for improved disease resistance in one environment may be more susceptible to the same disease in a different environment. Therefore, selection programs may have to be environment specific with the selection environment matching the commercial production environment. Breeders face challenge to accurately identify the phenotype for disease resistance and constraint is the potential cost associated with measuring disease resistance.

\section{A. Direct selection for disease resistance:} As per Rothschild (1998), it includes subclinical or clinical infection and clinical expression but it is not ethical at all. Animals with clinical expression of the infection may be identified with relative accuracy but all healthy animals may not be exposed to the pathogen or challenged equally. Moreover, exposure to the infection in natural environments is subject to temporal and spatial clustering of disease incidence as diseases often occur in clusters of time (years, seasons, production cycles, etc.) and space (herd, pasture, farm, region, etc.). In seasons when the disease incidence is high, there can be an increase in the accuracy of identifying animals with a high probability of being disease resistant but in seasons of low incidence the accuracy will be diminished (Snowder et al., 2005). Though this approach provides reliable measure of the phenotype, but ideally it should take place in a highly controlled and isolated environment, hence not practical the approach. The second approach is to uniformly challenge all breeding stock with infection which requires isolation of the population to prevent transmission to nonbreeding stock. This approach can be costly depending upon the pathogen's virulence and clinical expression of the disease but is a reliable measure of disease resistance. A third approach is to challenge relatives or clones of the breeding stock while the disease has a high mortality rate, and is a 
reliable method of determining genetic resistance. The latter two approaches are not without error because immunological background (previous exposure to the pathogen) may vary among animals which is to be determined for biasing the observed animal response to a disease challenge. In cattle, direct selection for reducing brucellosis had a favorable response as evidenced when Templeton et al. (1990) bred cows to a naturally resistant bull.

\section{B. Indirect selection for disease} resistance: It could be achieved by selecting for indicators of disease resistance which include pathogen products (i.e. pathogen reproductive rates, pathogen byproducts), and biological or immunological responses of the host. One of the most successful approaches of indirect selection for disease resistance was reported in sheep by selecting for low fecal internal parasite egg count (Woolaston et al., 1992). In dairy cattle, somatic cell count is used as a selection criterion for reducing mastitis (Shook and Schutz, 1994). A higher haemolytic complement activity can be an indicator for higher resistance to tick infestation and subsequent tick borne diseases (Wambura et al., 1998). Immune responsiveness, challenging an animal with an antigen or vaccine and measuring in vivo antibody response or production is an indicator of disease resistance (Buschmann et al., 1985; Gavora and Spencer, 1983) and has been most useful in poultry (Lamont et al., 2003) and swine (Mallard et al., 1992). Hernandez et al. (2003) suggested that immune responsiveness would be a useful indicator of disease resistance in cattle. One of the important non-pathogenic multideterminant antigens to monitor immune responsiveness in poultry is sheep erythrocytes (SRBC) (Siegel and Gross, 1980). Birds eliciting higher antibody response against SRBC also produce more antibodies to a variety of antigens (Parmentier et al., 1998). The non-specific components of immune system include phagocytic and bactericidal actions of peripheral blood monocytes, macrophages, lysozyme (Das et al., 2016; Lacey et al., 1990), and neutrophil metabolic and phagocytic activity and lymphocyte blastogenesis in response to antigens. Use of mitogens as an indicator of cellmediated response revealed genetic differences in poultry for $\mathrm{T}$ cell mitogens phytohaemagglutinin and concanavalin (reviewed in Ilaya Bharathi et al., 2016; Buschmann et al., 1985). The IgG is the most abundant immunoglobulin in serum and regarded as an indicator of general immune response (Pinard van der Laan et al., 1998). The bird's ability to mount antibody responses to other antigen is primarily revealed by serum IgG concentration which is traceable in all body fluids. van der Zijpp (1983) detailed the genetic components involved in immune response and resistance to viruses causing Marek's disease, lymphoid leukosis and Newcastle disease. Meeker et al. (1987) found no evidence for nonadditive genetic control (heterosis) of immune response to Pseudorabies or B. bronchiseptica vaccines, 
but additive genetic control and breed differences. Edfors et al. (1985) reported significant sire effects on immune response, indicating genetic influence of immune response to $E$. coli antigens. Further investigations (Kokate et al., 2017abc; Das et al., 2016; Gupta et al., 2010; Sivaraman et al., 2005) revealed that humoral response to antigens like SRBCs, ND vaccine, GAT etc. had polygenic inheritance with moderate heritability estimates, cell mediated immune response had polygenic inheritance with low to moderate heritability estimates, phagocytosis had additive gene control with major gene effect, and combining all these three facets constitute immunocompetence index. Gavora and Spencer (1983) suggested that the heritability estimates of the humoral immune response correspond well to resistance to a disease caused by a particular pathogen. Of course, the estimates of heritability do not indicate which genes or how many genes are involved in the control of a particular trait, however, demonstrate which diseases have a strong additive genetic component, and would therefore be most responsive to breeding for increased disease resistance (Warner et al., 1987). Selection for immune response is generally beneficial when a single disease is targeted. For effective selection, indicator traits must be heritable, highly genetically correlated with resistance to the disease or diseases of interest, accurate to measure, and affordable.
C. Genomic selection for disease resistance: Genomic selection for genetic resistance to disease needs identification of specific resistance genes or genetic markers linked to the phenotypes of disease resistance trait and the benefit of this approach is the ability to select animals using DNA-based selection without exposure to infection in a challenge test, or necessity of a natural epidemic (Bishop and Woolliams, 2014). This can be achieved if major genes or QTL for resistance can be identified, or SNP-chip based genomic predictors (Meuwissen et al., 2001) of sufficient accuracy developed. Without DNA-based predictions, selection accuracy will depend on either routine challenge testing or continuous disease prevalence in the field, to enable calculation of expected breeding values (EBVs) based on expressed resistance phenotypes (Bishop and Woolliams, 2014). The complexity of the immune system clearly infers that many single genes, major genes, MHC and nonMHC genes are involved in disease resistance and can be exploited for screening of resistance and selection. Few examples of single genes influencing disease resistance in livestock include the fimbriae F4 (K88) gene in swine for reducing $E$. coli intestinal infection (Moon et al., 1999), the prion protein (PrP) gene related to scrapie susceptibility in sheep (Bossers et al., 1999), and the TNC gene related to salmonellosis in chickens $(\mathrm{Hu}$ et al., 1997). The Nramp1 gene (natural resistance-associated macrophage protein) associated with innate immune system gets 
linked with resistance to brucellosis (Harmon et al., 1989), tuberculosis and salmonellosis (Qureshi et al., 1996). Homologues for Nramp1 was identified, sequenced and/or mapped in chickens, swine and sheep (Adams and Templeton, 1998). B-haplotype ( $\mathrm{B}^{21}$ allele) associated with MD resistance (Bacon and Witter, 1994; Hedemand et al., 1993), Tv and ev genes controlling/influencing resistance to ALV (Payne and Nair, 2012; Bacon et al., 2000) are few examples of major genes. Variability within BoLA complex provides an opportunity for identifying alleles with significant effect on the expression of resistance to mastitis (Yongerman and Saxton, 2004). Particular loci on OLA complex are associated with genetic resistence to parasites, such as Haemonchus contortus, Trichostrongyus columbriformis and Ostertagija circumcinta in sheep (Jovanovic et al., 2009). Class II MHC genes are associated with MD and Coccidia resistance, Class IV with Coccidia resistance and $\mathrm{B}-\mathrm{F} / \mathrm{B}-\mathrm{L}$ region genes with resistance and susceptibility to pathogens. The B complex was reported to be associated with resistance to Marek's disease, Rous Sarcoma virus, fowl cholera, and lymphoid leukosis viruses (van der Zijpp, 1983), and the immune response to synthetic antigens, bovine serum albumen, Salmonella pullorum bacterium, total IgG levels, and cell-mediated responses (Lamont and Dietert, 1990). The examples of non-MHC genes are Cytokine genes (IFN gamma and IL-2), Cytokine promoter genes (IFN gamma and IL-2 gene promoter), Cytokine Receptor gene (IL-2 $\gamma$ receptor), Toll-like receptors, Chemokines, Inducible Nitric oxide, Arginase etc. Cytokines have regulatory and signaling role in immune responses. The abnormal levels of IL-2 are associated with many disease problems or immune disorder, and polymorphism at regulatory sequences is associated with antibody response. SNP (2781G $>$ T) IFN- $\gamma$ gene in Holstein, Jersey and Brahman-Angus crosses has association with Mycobacterium avium subspecies paratuberculosis (MAP) infection (Pinedo et al., 2009). Toll-like receptor (TLR) activation on antigen presenting cells results in the production of numerous cytokines such as IL-12 and IL10, and chemokines such as CXCLi2 and CCLi2, and critical to this innate immune response is the signal transduction

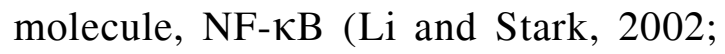
Luster, 2002). Chemokines affect growth and differentiation of haematopoetic cells and its normal expression is necessary for the host defense. Inducible nitric oxide/ NO synthase type 2 (NOS- 2 or iNOS) has a role in immunity against viruses (Herpes simplex type-1, Vaccinia, Japanese encephalitis), bacteria (tuberculosis) and parasites (leishmania, malaria). For example, bovine CARD15/NOS-2 (chromosome 18) plays an important role in TB resistance (Cheng et al., 2016; Qin et al., 2015). In pathological conditions like asthma, arthritis, Psoariasis, diabetic complications, trauma, breast cancer, glomerulonephritis and infectious diseases, there is enhanced activity of arginase, and 
selective arginase inhibitors or down regulation of arginase can be a control measure of such disases.

New and novel gene mapping approaches are being developed specifically for detection of complex disease loci (Pareek et al., 2002). Micro array technology is advancing rapidly to enable association of livestock DNA with mice and human DNA (Chitko-McKown et al., 2004). Global gene expression profiling with the help of Microarray unravels that NFKBID, BoLADQB, HOXA13, PAK1, TGFBR2, NFKBIA genes are associated with $T$. annulata infection (Kumar et al., 2017). Comparative genomics may make the identification of disease loci easier and more affordable.

Marker-assisted selection (MAS): The genetic markers can be used to locate genes underlying phenotypic traits on the corresponding genome maps using linkage strategies. This mapping is the first step in the process referred to as positional cloning which culminates in the isolation of the causal gene and mutation. The novel marker assisted selection scheme strives for identification of quantitative trait loci (QTL) (Wilmut et al., 1992) and is expected to increase genetic response by affecting the factors: increase genetic variation (the molecular substrate of breeding programs), increase the accuracy of selection, reduce the generation interval and increase the selection intensity. Mapping genes explaining breed differences for economically important traits and disease resistance are potential for the gene introgression by marker aided backcrossing, thus increasing the genetic variation usable as substrate for selection programs. Adding information on mapped QTL on top of their own performance data and that of relatives will increase accuracy of selection especially by explaining Mendelian sampling variance. As the marker genotype is obtainable at virtually any stage of development and irrespective of sex, there is considerable potential for reduction in generation interval. Finally, marker genotyping will become considerably cheaper than phenotype collection allowing selection for more traits amongst more individuals than the conventional approach, thus increasing the selection differential or intensity. For epidemic diseases, it is necessary to develop techniques for selection based on marker alleles associated with enhanced disease resistance (Bishop and Woolliams, 2014). Moreover, understanding the molecular biology underneath complex traits might reveal novel mechanisms of gene action requiring adjusted selection schemes for their optimal exploitation. Selection for resistance based on specific $\mathrm{B}$ alleles within the MHC has been used for many years to assist in the management of the Marek's disease. Researchers have identified a number of QTL associated with resistance to the disease (Yonash et al., 2001) and markers for dermatophilosis in cattle (Maillard et al., 2003), scrapie in sheep (Hunter et al., 1996), diarrhoea caused by 
E. coli in pigs (Edfors and Wallgren, 2000). Attempts are being made to explore many markers (reviewed in Prajapati et al., 2017) for its accurate implication for selection of the traits of disease resistance or susceptibility, such as SNP G29A mutation in the $5^{\prime}$ UTR of the ITGB6 gene (chromosome 2) associates with resistance to FMD infection in the zebu cattle (Singh et al., 2014), ATP1A1 (chromosome 3) polymorphism with the mastitis trait in Holstein cows (Liu et al., 2012), bovine CARD15/NOS-2 (chromosome 18) with TB susceptibility (Cheng et al., 2016; Qin et al., 2015). In piglets, a receptor (K88) in the intestinal tract to which a particular strain of E.coli adheres, being genetically determined, a commercially available DR2 gene marker test allows routine identification of genetically resistant individuals, and a DR1 gene marker test further identifies those individuals susceptible to F18 E. coli. The utilization of these tests during breeding practices has significantly increased genetic resistance in those populations where it has been implemented (Edfors and Wallgren, 2000).

\section{Breeding strategy for resistance to diseases}

For practical purposes, investigators will normally focus their attention on two phenotypic disease susceptibility classes (afflicted/ not afflicted animals) in which continuous variation is disregarded. However, due to the existence of unknown continuity-causing factors which become noticeable above certain threshold level, disease susceptibility may vary discontinuously, thus necessitating genetic analyses to be carried out quantitatively rather than qualitatively (Muller and Brem, 1991). The continuous variable underlying these phenomena has been termed as liability. Falconer (1967) has calculated the correlation of liability between relatives of any specified sort and the heritability. If a trait like disease resistance must be included in a breeding programs, animal breeders will have to consider genetic variability and heritability, economic value, possibilities and costs for recording data and exploitation of of marker traits and genes. Although disease trait heritabilities are normally low, the genetic variation of disease incidence is economically important and justifies the inclusion of disease traits in breeding programs (Muller and Brem, 1991). Progress in resistance breeding requires long-term strategies, and is limited and delayed by at least two factors: inadvertent enhancement of susceptibility to a disease by selection for specific resistance to another disease, and lack of strategies allowing selection for overall resistance. Conventional breeding strategies for disease resistance whereas has at least two advantages: automatic inclusion of all genetic host factors influencing resistance or susceptibility, and selection for the resistant trait being independent of shifts in environmental factors and disease profiles over time. Although it has the principal disadvantages of low heritability of resistance traits necessitating expensive progeny testing with prolonged generation 
intervals, moderately defined heterogeneity of the disease traits, and antagonistic relationship of resistance and performance traits (Muller and Brem, 1991). Depending upon disease etiology and the availably animal genetic resources, the strategy for advancing genetic control of disease can be established through the selection of locally adapted breeds, the implementation of cross-breeding methods geared at introducing genes significant in the expression of genetic resistance/tolerance towards pathogens, and the selection of individuals highly resistant to pathogens (Jovanovic et al., 2009).

Selective breeding to take advantage of within breed variation in disease resistance is an important strategy in the control of a number of diseases. For endemic diseases, which are a continuously present in the relevant production systems (e.g. mastitis, helminthosis), selection based on phenotypic response to disease challenge is possible. The indicator traits of disease resistance are routinely recorded in dairy herds, and their variation has a large genetic component. With the previously presented evidence of genetic control of immune responsiveness and the obvious natural selective advantage of resistant animals, it would seem inevitable that selective breeding for improved production traits would have improved resistance in animals. This has not been the case. One reason might be that modern management, which includes vaccination, preventive medication and separation of animals from pathogens, masks the genetic capacity of the animals to resist disease. In addition, some genes may have pleiotropic effects antagonistic to improving both production traits and resistance (Warner et al., 1987). The existence of an antagonistic relationship between genetic merit for production traits and susceptibility to the disease has promoted interest in selection for resistance. Information on genetic correlations among disease resistance, immune response parameters and production traits are scarce. Gavora and Spencer (1978) explains that it is impossible to distinguish between effects due to disease and those due to genetic potential when estimating genetic correlations in populations where disease is present. Many dairy cattle breeding programs, therefore, include increasing resistance to mastitis as an objective. Interest is growing in integrated parasite management (IPM) programs, of which breeding for genetic resistance is a component. Selective breeding of sheep on the basis of faecal egg count (FEC) would be an effective means of reducing the need for treatment with anthelmintics and of reducing the contamination of pastures with the eggs of nematode parasites (Woolaston and Windon, 2001).

Keeping critical view upon dissection of genetics of disease resistance in livestock, its production parameters and sustainable maintenance of resistance and animal production, we suggest the breeding strategy taking consideration of these following initiatives: 
(a) Selection of locally adapted breeds taking their intrinsic evolutionary advantage,

(b) Selection of those parents that produce the progeny with the lowest incidence of disease,

(c) Genetic selection of animals for high immune response using an index that combines estimated breeding values for several immunological traits or genetic markers for QTL analysis,

(d) Selective breeding to take advantage of within breed variation in disease resistance,

(e) Use of a breeding stock possessing certain MHC alleles, which are involved in the regulation of the immune response, including immune function traits with high heritability in breeding programs,

(f) Introgresion of disease resistance genes into the productive breeds followed by MAS aided backcrossing with the resistant individual as recurrent parent,

(g) Maintaenance of genetically heterogenous populations.

After all, present strategy strives for sustainable control of diseases by integration of herbal chemotherapeutic agents and antibiotics management, vaccination protocols, grazing management, nutritional management, culling and stress reduction practices, biological and genetic control understanding the host-pathogen interaction.
Genetic modification approach for disease resistance

Genetic modification offers alternative strategy to traditional animal breeding and is likely to have speciûc application where genetic variation does not exist in a given population or species and where novel genetic improvements can be engineered (Whitelaw and Sang, 2005). With either approach, the intention would be to enhance the ability of the animals to mount an appropriate immune response against the pathogen (which could require dampening down the immune system at strategic stages) or to generate an effective system that would directly block pathogen entry or directly destroy the pathogen (Whitelaw and Sang, 2005). For instance, the Mx genes in mice has the functional alleles to induce a potent antiviral state in response to infection by specific groups of viruses, including influenza (Whitelaw and Sang, 2005), whereas in most commercial chicken lines, the allele of Mx gene is apparently not functional due to a single amino acid substitution (Ko et al., 2002). There are various possible strategies, as listed below, and the authors anticipate that current efforts in disease biology will enable more to be devised:

Dominant-negative proteins: The introduction of mutant versions of key factors in pathogen infection, such as cell surface receptors, can block disease progression (Ono et al., 2004).

RNA interference (RNAi): This strategy 
relies on the ability of speciûc short RNA sequences to anneal with the RNA of the pathogen, causing destruction of the foreign RNA. RNAi requires access to the target RNA, which may limit this approach to viruses (Clark and Whitelaw, 2003; Tiscornia et al., 2003).

RNA decoys: Expression of RNA sequences that mimic speciûc sequences within a pathogen can disrupt the activity of the pathogen's replication machinery (Luo et al., 1997). Again, this approach is probably restricted to specific viruses, with influenza being a good candidate.

Immunomodulation by CpG motifs: Bacterial DNA contains non-methylated cytosine-phosphodiester-guanine $(\mathrm{CpG})$ dinucleotide motifs in higher frequency, when introduced in mammalian system recognized as danger signals for pathogen associated molecular pattern (PAMP) (Medzhitov and Janeway, 2000) and immune response is induced. In mammals, $\mathrm{CpG}$ are less in frequency, $\mathrm{C}$ is methylated and $\mathrm{C}$ is upstream and $\mathrm{G}$ is downstream to $\mathrm{CpG}$, which suppress stimulatory properties. Synthetic olignodeoxynucleotides (ODN) (motif: 52 $\mathrm{X}_{1} \mathrm{X}_{2} \mathrm{CGY}_{1} \mathrm{Y}_{2} 32$, where $\mathrm{X}_{1}$ is a purine, $\mathrm{X}_{2}$ is a purine or $\mathrm{T}$ and $\mathrm{Y}_{1}$ and $\mathrm{Y}_{2}$ are pyrimidines; GTCGTT: optimal motif and AACGTT: suboptimal motif, as recognized by TLR-9) may be used for immune stimulation as it has potent immunostimulatory effect in numerous vertebrate species. The CpG-ODN stimulate B-cells, monocytes, macrophages, dendritic cells, NK cells, upregulate MHC I \& II and cytokines and in vitro activity of CpG-ODN is species-specific (Babiuk et al., 2003; Krieg, 2002; Klinman et al., 1996). Prior administration of CpG-ODN protects against bacteria (L. monocytogenis, $E$. coli etc.), enhance innate immunity and can enhance immunogenecity of DNA vaccines (Krieg, 2002). CpG-ODN can shift the immune response to a Th1-dominated cytokine pathway thus explaining the predominance of Th1-like responses when CpG-ODN is used as an adjuvant with subunit or conventional vaccines (Zimmermann et al., 1998; Chu et al., 1997).

Transgenic breeding: While conventional breeding strategies as well as MAS are restricted to the exploitation of genetic variation pre-existing within the species, if not breed of interest, transgenics has opened the exciting possibility to exploit variants across species barriers or even create de novo. The approach of gene targeting of totipotent embryonic stem cells in culture followed by either nuclear transfer in enucleated oocytes or microinjection into blastocysts mediated by homologous recombination is locus-specific for the production of transgenic animals (Campbell et al., 1996). Besides enhancing growth and improving carcass characteristics, wool production, milk production and altering milk composition, transgenic breeding could increase disease resistance in livestock. However, the application of 
transgenics applied to livestock species has proven most successful so far in the area of gene-pharming or the use of livestock species as expression systems for the production of high value protein products. The transgenic production of antibodies in the host animal may act in an analogous manner to vaccination (Kolb et al., 2001; Sola et al., 1998).

It may be concluded that enhancement in genetic resistance to diseases may be given due emphasis for maintaining a balance between production and disease resistance status of animals. The potential seems great for identifying breeding stock that is healthier because of their immune responsiveness. Although it may be difficult to select for animals' resistance to a wide range of diseases, it may be possible to

\section{REFERENCES}

Adams LG and Templeton JW, 1998. Genetic resistance to bacterial diseases of animals. Rev Sci Tech Off Int Epiz, 17: 200-219

Babiuk LA, Gomis S and Hecker R, 2003. Molecular approaches to disease control. Poult Sci, 82: 870-875

Bacon LD and Witter RL, 1994. Serotype speciûcity of B haplotype inûuence on the relative efûcacy of Marek's disease vaccines. Avian Dis, 38: 65-71

Bacon LD, Hunt HD and Cheng HH, 2000. A review of the development of chicken lines to resolve genes determining breed or identify animals that are genetically more responsive to multideterminant antigens or vaccines. Suitable molecular marker or marker traits may be identified for marker-assisted selection and developing disease resistant populations. Certainly, genetic selection will not solve all of our livestock disease problems. Therefore, integration of chemotherapeutic agents and antibiotics management, vaccination protocols, grazing management, nutritional management, culling and stress reduction practices along with other measures must accompany genetic approaches to reduce the impact of livestock disease on profitability and animal well being. The research efforts may be further strengthened for better understanding of genetic mechanisms of diseases resistance vis a vis production.

resistance to diseases. Poult Sci, 79: 1082-1093

Bishop SC, De Jong M and Gray D, 2002. Opportunities for incorporating genetic elements into the management of farm animal diseases: policy issues. Commission on Genetic Resources for Food and Agriculture, FAO, Rome, pp36

Bishop SC and Stear MJ, 2003. Modeling of host genetics and resistance to infectious diseases: understanding and controlling nematode infections. Vet Parasitol, 115: 147-166 
Bishop SC, 2012. A consideration of resistance and tolerance for ruminant nematode infections. Front Livest Genomics, 3: 168/1-7; https://doi.org/ 10.3389/fgene.2012.00168

Bishop SC and Woolliams JA, 2014. Genomics and disease resistance studies in livestock. Livest Sci, 166: 190-198

Bossers ME, Harders FL and Smits MA, 1999. PrP genotype frequencies of the most dominant sheep breed in a country free from scrapie. Archiv Virol, 144: 829-834

Buschmann H, Kransslich H, Herrmann H, Meyer J and Kleinschmidt A, 1985. Quantitative immunological parameters in pigs- Experiences with the evaluation of an immunocompetence profile. Z. Tierz. Zuchtungsbiol, 102: 189-199

Campbell KHS, McWhir J, Ritchie WA and Wilmut I, 1996. Sheep cloned by nuclear transfer from a cultured cell line. Nature, 380: 64-66

Cheeseman JH, 2007. Avian immunology, immunogenetics, and host immune response to Salmonella enterica serovar enteritidis infection in chickens. Retrospective Thesis and Dissertations. 15855. https://lib.dr.iastate.edu/rtd/ 15855 .

Cheng Y, Huang C and Tsai HJ, 2016. Relationship of bovine NOS-2 gene polymorphisms to the risk of bovine tuberculosis in Holstein cattle. J Vet Med Sci, 78(2): 281-286
Chitko-McKown CG, Fox JM, Miller LC, Heaton MP, Bono JL et al., 2004. Gene expression profiling of bovine macrophages in response to Escherichia coli 0157:H7 lipopolysaccharide. Dev Comp Immunol, 28: 636-645

Chu RS, Targoni OS, Krieg AM, Lehmann PV and Harding CV, 1997. CpG oligodeoxynucleotides act as adjuvants that switch on T helper 1 (Th1) immunity. J Exp Med, 186: 1623-1631

Clark J and Whitelaw B, 2003. A future for transgenic livestock. Nature Rev Genet, 4(10): $825-833$

Damoiseaux JG, Cautain B, Bernard I, Mas M, van Breda Vriesman PJ et al., 1999. A dominant role for the thymus and MHC genes in determining the peripheral CD4/CD8 $\mathrm{T}$ cell ratio in the rat. J Immunol, 163: 2983-2989

Das AK, Kumar S, Mishra AK, Rahim A and Kokate LS, 2016. Estimating genetic parameters of immunocompetent traits in Rhode Island Red chicken. Ind J Anim Sci, 86(9): 1015-1020

Davies G, Genini S, Bishop SC and Giuffra E, 2009. An assessment of the opportunities to dissect host genetic variation in resistance to infectious diseases in livestock. Animal, 3: 415436

Doeschl-Wilson AB, Bishop SC, Kyriazakis I and Villanueva B, 2012. Novel methods for quantifying individual host response to infectious pathogens for 
genetic analyses. Front Livest Genomics, 3: 266/1-9; doi: 10.3389/ fgene. 2012.00266

Edfors LI, Gahne B and Petersson H, 1985. Genetic influence on antibody response to two Escherichia coli antigens in pigs. II. Difference in response between paternal half-sibs. Z. Tierz. Zuchtunsbiol, 102: 308-3017; https://doi.org/10.1111/ j.1439-0388.1985.tb00 700.x

Edfors LI and Wallgren P, 2000. Escherichia coli and Salmonella diarrhoea in pigs, In: Axford RFE et al. (Ed.) 2000. Breeding for resistance in farm animals. Wallingford, Oxon, UK; CABI Pub (New York), pp253-267

Falconer DS, 1967. The inheritance of liability to diseases with variable age of onset, with particular reference to diabetes mellitus. Am J Hum Genet, 31: 1-20

FAO DAD-IS, 2007. The state of Agricultural biodiversity in the livestock sector: Animal genetic resources and resistance to disease. Section E, pp101-111

Gavora JS and Spencer JL, 1978. Breeding for genetic resistance to disease: Specific or general? World's Poult Sci J, 34: 137-148

Gavora JS and Spencer JL, 1983. Breeding for immune responsiveness and disease resistance. Anim Blood Gr Biochem Genet, 14: 159-180, https://doi.org/ 10.1111/j.1365-2052.1983.tb01070.x

Grenfell BT and Dobson AP, 1995. Ecology of infectious diseases in natural populations. Cambridge University Press, Cambridge, UK

Gupta T, Kumar S, Prasad Y and Kataria MC, 2010. Genetics of immunocompetence traits in White Leghorn chicken divergently selected for humoral response to sheep erythrocytes. Ind $\mathbf{J}$ Poult Sci, 45(1): 18-21

Harmon BG, Adams LG, Templeton JW and Smith R, 1989. Macrophage function in mammary glands of Brucella abortusinfected cows and cows that resisted infection after inoculation of Brucella abortus. Am J Vet Res, 50: 459-465

Hedemand JE, Sorensen P, Ducro BJ and Simonsen M, 1993. Resistance to Marek's disease associated with $\mathrm{B}^{21}$ like haplotypes. Archiv fur Geflugelkunde, 57(2): 73-76

Hernández A, Karrow N and Mallard BA, 2003. Evaluation of immune responses of cattle as a means to identify high or low responders and use of a human microarray to differentiate gene expression. Genet Select Evol, 35: S67-S81

Hu J, Bumstead N, Burrow P, Sebastiani G, Olien L et al., 1997. Rsistance to salmonellosis in the chicken is linked to Nramp1 and TNC. Genom Res, 7: 693-704

Hunter N, Foster JD, Goldmann W, Stear MJ, Hope J et al., 1996. Natural scrapie in a closed flock of Cheviot sheep occurs only in specific PrP genotypes. Arch Virol, 141: 809-824 
Ilaya Bharathi D, Raj Manohar G and Shamsudeen P, 2016. Selection methods for disease resistance in poultry- An overview. Int J Sci Envir Technol, 5: 810-815

Jovanovic S, Savic M and Zivkovic D, 2009. Genetic variation in disease resistance among farm animals. Biotech Anim Husb, 25(5-6): 339-347

Klinman DM, Yi AK, Beaucage SL, Conover J and Krieg AM, 1996. CpG motifs present in bacterial DNA rapidly induce lymphocytes to secrete interleukin 6, interleukin 12, and interferon gamma. Proc Nat Acad Sci USA, 93: 2879-2883

Ko JH, Jin HK, Asano A, Takada A, Ninomiya A et al., 2002. Polymorphisms and the differential antiviral activity of the chicken Mx gene. Genom Res, 12(4): 595-601

Kokate LS, Kumar S, Rahim A and Das AK, $2017 \mathrm{a}$. Investigating immunocompetence in Aseel, Kadaknath and White Leghorn chicken. Ind J Anim Sci, 87(1): 35-38

Kokate LS, Kumar S, Rahim A and Das AK, 2017b. Estimating serological immune response against Newcastle disease vaccine in Aseel, Kadaknath and White Leghorn chicken using haemagglutination inhibition test. Ind J Anim Sci, 87(2): 136-138

Kokate LS, Kumar S, Rahim A and Das AK, 2017c. Kinetics of serum antibody response to Newcastle disease vaccine in Aseel, Kadaknath and White Leghorn chicken using ELISA. Ind J Anim Sci, 87(2): $168-170$

Kolb AF, Pewe L, Webster J, Perlman S, Whitelaw CBA et al., 2001. Virusneutralizing monoclonal antibody expressed in milk of transgenic mice provides full protection against virusinduced encephalitis. J Virol 75(6): 2803-2809

Krieg AM, 2002. CpG motifs in bacterial DNA and their immune effects Ann Rev Immunol, 20: 709-760

Kumar A, Gaura G, Gandham R, Panigrahi M, Ghosh S et al., 2017. Global gene expression profile of peripheral blood mononuclear cells challenged with Theileria annulata in crossbred and indigenous cattle. Infection, Genet Evol, 47: 9-18

Lacey C, Wilkie BN, Kennedy BW and Mallard BA, 1990. Genetic and other effects on bacterial phagocytosis and killing by cultured peripheral blood monocytes of SLA defined miniature pigs. Anim Genet, 20: 371-382

Lamont SJ, 1991. Immunogenetics and the major histocompatibility complex. Vet Immunol Immunopathol, 30: 121-127

Lamont SJ, Pinard van der Laan MH, Cahaner $\mathrm{A}$, van der Poel JJ and Parmentier HK, 2003. Selection for disease resistance: direct selection on the immune response. In: Muir WM and Aggrey SE (Ed.). Poultry Genetics, Breeding and 
Biotechnology. CABI Publishing. pp399-418

Lamont SJ and Dietert RR, 1990. Immunogenetics. In: Crawford RD (Ed.). Poultry Breeding and Genetics. Elsevier, Amsterdam.

Li X and Stark GR, 2002. NFkB-dependent signaling pathways. Exper Hematol, 30: 285-296

Liu YX, Xu CH, Gao TY and Sun Y, 2012. Polymorphisms of the ATP1A1 gene associated with mastitis in dairy cattle. Genet Mol Res, 11(1): 651-660

Luo G, Danetz S and Krystal M, 1997. Inhibition of influenza viral polymerases by minimal viral RNA decoys. J Gen Virol, 78(Pt 9): 2329-2333

Luster AD, 2002. The role of chemokines in linking innate and adaptive immunity. Curr Opin Immunol, 14: 129-135

Maillard JC, Berthier D, Chantal I, Thevenon S, Sidibe I et al., 2003. Selection assisted by a BoLA-DR/DQ haplotype against susceptibility to bovine dermatophilosis. Genet Select Evol, 35 (Suppl. 1): S193-S200

Mallard BA, Wilkie BN, Kennedy BW and Quinton M, 1992. Use of estimated breeding values in a selection index to breed Yorkshire pigs for high and low immune and innate resistance factors. Anim Biotech, 3: 257-280

Medzhitov R and Janeway C Jr, 2000. Innate immune recognition: mechanisms and pathways. Immunol Rev, 173: 89-97

Meeker DL, Rothschild MF, Christian LL, Warner CM and Hill HT, 1987. Genetic control of immune response to pseudorabies and atrophic rhinitis vaccines: I. Heterosis, general combining ability and relationship to growth and backfat. J Anim Sci, 64: 407-413

Meuwissen THE, Hayes BJ and Goddard ME, 2001. Prediction of total genetic value using genome-wide dense marker maps. Genet, 157: 1819-1829

Moon HW, Hoffmann LJ, Cornick NA, Boother SL and Bosworth BT, 1999. Prevalences of some virulence genes among Escherichia coli isolates from swine presented to a diagnostic laboratory in Iowa. J Vet Diag Invest, 11: $557-560$

Muller M and Brem G, 1991. Disease resistance in farm animals. Experientia, 47: 923-929

Ono E, Amagai K, Taharaguchi S, Tomioka Y, Yoshino S et al., 2004. Transgenic mice expressing a soluble form of porcine nectin-1/herpesvirus entry mediator $\mathrm{C}$ as a model for pseudorabiesresistant livestock. Proc Nat Acad Sci USA, 101(46): 16150-16155

Pareek CS, Pareek RS and Walawski K, 2002. Novel linkage mapping approach using DNA pooling in human and animal genetics I. detection of complex disease loci. J Appl Genet, 42: 175-192 
Parmentier HK, Walraven $\mathrm{M}$ and Nieuwland MGB, 1998. Antibody response and body weights of chicken lines selected for high and low humoral responsiveness to sheep red blood cells. 1. Effect of E.coli lipopolysaccharide. Poult Sci, 77: 248-255

Payne LN and Nair V, 2012. The long view: 40 years of avian leukosis research. Avian Pathol, 41(1): https://doi.org/ 10.1080/03079457.2011.646237

Pinard van der Laan MH, Siegel PB and Lamont SJ, 1998. Lessons from selection experiment on immune response in the chicken. Avian Poult Biol Rev, 9: 125-141

Pinedo PJ, Buergelt CD, Donovan GA, Melendez P, Morel L et al., 2009. Association between CARD15/ NOS2 gene polymorphisms and paratuberculosis infection in cattle. Vet Microbiol, 134(9): 346-352

Prajapati BM, Gupta JP, Pandey DP, Parmar GA and Chaudhari JD, 2017. Molecular markers for resistance against infectious diseases of economic importance. Vet World, 10(1): 112-120

Qin B, Liu T, Xu C, Dong G, Wang S et al., 2015. Correlation study of CARD15 gene style polymorphism and susceptibility of tuberculosis in dairy cows. China Anim Husb Vet Med, 42(6): 1553-1558

Qureshi T, Templeton JW and Adams LG, 1996. Intracellular survival of Brucella abortus, Mycobacterium bovis (BCG), Salmonnella dublin and Salmonella typhimurium in macrophages from cattle genetically resistant to Brucella abortus. Vet Immunol Immunopathol, 50: 55-66

Reiner G, 2009. Investigations on genetic disease resistance in swine- A contribution to the reduction of pain, suffering and damage in farm animals. Appl Anim Behav Sci, 118: 217-221

Rothschild MF, 1998. Selection for disease resistance in the pig. Proc Nat Swine Improv Fed, Raleigh, North Carolina

Savic M, Jovanovic S and Trailovic R, 1995. Some genetic markers in blood of Balkan goat. Acta Veterinaria, 45: 5-6

Selvam R and Panneerselvam S, 2014. Genetics of disease resistance in livestock- the concepts and applications. Aayvagam Int J Multidisc Res, 2A (5): 15-18

Shook GE and Schutz MM, 1994. Selection on somatic cell score to improve resistance to mastitis in the United States. J Dairy Sci, 77: 648-658

Siegel PB and Gross WB, 1980. Production and persistence of antibodies in chickens to sheep erhtyrocytes. I. Directional selection. Poult Sci, 59(1): 1-5

Singh R, Kumar S, Deb R, Sengar G, Singh U et al., 2014. Development of a tetraprimer ARMS PCR-based assay for 
detection of a novel single-nucleotide polymorphism in the 52 untranslated region of the bovine ITGB6 receptor gene associated with foot and-mouth disease susceptibility in cattle. Archiv Virol, 159: 3385-3389

Sivaraman GK, Kumar S, Saxena VK, Singh NS and Shivakumar BM, 2005. Genetics of immunocompetent traits in a synthetic broiler dam line. British Poult Sci, 46(2): 169-174

Snowder GD, van Vleck LD, Cundiff LV and Bennett GL, 2005. Influence of breed, heterozygosity and disease incidence on estimates of variance components of respiratory disease in pre-weaned beef calves. J Anim Sci, 83: 507-518

Sola I, Castilla J, Pintado B, Sanchez-Morgado JM, Whitelaw CB et al., 1998. Transgenic mice secreting coronavirus neutralizing antibodies into the milk. J Virol, 72(5): 3762-3772

Springbett J, Mackenzie K, Woolliams A and Bishop SC, 2003. The contribution of genetic diversity to the spread of infectious diseases in livestock populations. Genet, 165: 1465-1474

Stowe KA, Marquis RJ, Hochwender CG and Simms EL, 2000. The evolutionary ecology of tolerance to consumer damage. Ann Rev Ecol Systematics, 31(1): 565-595

Templeton JW, Estes DM, Price RE, Smith R and Adams LG, 1990. Immunogenetics of natural resistance to bovine brucellosis. In: Proc $4^{\text {th }}$ World Cong

Genet Appl Livest Prod, pp396-399

Tiscornia G, Singer O, Ikawa M and Verma IM, 2003. A general method for gene knockdown in mice by using lentiviral vectors expressing small interfering RNAs. Proc Nat Acad Sci USA, 100(4): 1844-1848

van der Zijpp AJ, 1983. Breeding for immune responsiveness and disease resistance. World's Poult Sci J, 39: 118-131; https:/ /doi.org/10.1079/WPS19830012

van Meerwijik JP, Bianchi T, Marguerat S and MacDonald HR, 1998. Thymic lineage commitment rather than selection causes genetic variations in size of CD4 and CD8 compartments. J Immunol, 160: 3649-3654

Wambura PN, Gwakisa PS, Silayo RS and Rugaimukamu EA, 1998. Breed associated resistance to tick infestation in Bos indicus and their crosses with Bos taurus. Vet Parasitol, 77: 63-70

Warner CM, Meeker DL and Rothschild MF, 1987. Genetic control of immune responsiveness: A review of its use as a tool for selection for disease resistance. Anim Sci, 64: 394-406

Whitelaw CBA and Sang HM, 2005. Diseaseresistant genetically modiûed animals. Rev Sci Tech Off Int Epiz, 24 (1): 275283

Wilmut I, Haley CS and Woolliams JA, 1992. Impact of biotechnology on animal 
breeding. Anim Reprod Sci, 28: 149162

Woolaston RR, Elwin RL and Barger IA, 1992. No adaptation of Haemonchus contortus to genetically resistant sheep. Int J Parasitol, 22: 377-380

Woolaston RR and Windon RG, 2001. Selection of sheep for response to Trichostrongylus colubriformis larvae: genetic parameters. Anim Sci, 73: 4148

Yonash N, Cheng HH, Hillel J, Heller DE and Cahaner A, 2001. DNA microsatellites linked to quantitative trait loci affecting antibody response and survival rate in meat-type chickens. Poult Sci, 80: 2228

Yongerman SM and Saxton AM, 2004. Association of CXCR2 polymorphisms with subclinical and clinical mastitis in dairy cattle. Dairy Sci, 87: 2442-2481

Zimmermann S, Egeter O, Hausmann S, Lipford GB, Rocken M et al., 1998. $\mathrm{CpG}$ oligodeoxynucleotides trigger protective and curative Th1 responses in lethal murine leishmaniasis. J Immunol, 160: 3627-3630 